\title{
Data envelopment analysis based on team reasoning
}

DOI:

10.1111/itor. 12447

\section{Document Version}

Accepted author manuscript

Link to publication record in Manchester Research Explorer

\section{Citation for published version (APA):}

Xia, M., Chen, J., \& Zeng, X. (2017). Data envelopment analysis based on team reasoning. International Transactions in Operational Research. https://doi.org/10.1111/itor.12447

\section{Published in:}

International Transactions in Operational Research

\section{Citing this paper}

Please note that where the full-text provided on Manchester Research Explorer is the Author Accepted Manuscript or Proof version this may differ from the final Published version. If citing, it is advised that you check and use the publisher's definitive version.

\section{General rights}

Copyright and moral rights for the publications made accessible in the Research Explorer are retained by the authors and/or other copyright owners and it is a condition of accessing publications that users recognise and abide by the legal requirements associated with these rights.

\section{Takedown policy}

If you believe that this document breaches copyright please refer to the University of Manchester's Takedown Procedures [http://man.ac.uk/04Y6Bo] or contact uml.scholarlycommunications@manchester.ac.uk providing relevant details, so we can investigate your claim.

\section{OPEN ACCESS}




\title{
Data envelopment analysis based on team reasoning
}

\author{
Meimei Xia ${ }^{\mathrm{a}}$, Jian Chen ${ }^{\mathrm{b}}$, and Xiao-Jun Zeng ${ }^{\mathrm{c}}$ \\ ${ }^{\mathrm{a}}$ School of Economics and Management, Beijing Jiaotong University, Beijing 100044, China,

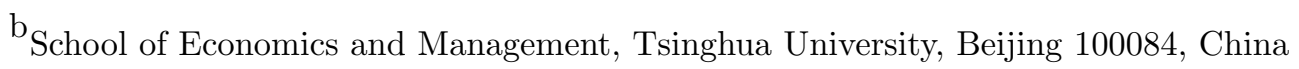 \\ ${ }^{\mathrm{c}}$ School of Computer Science, University of Manchester, Manchester M13 9PL, United Kingdom
}

\begin{abstract}
Existing approaches to data envelopment analysis (DEA) focus mainly on the derivation of the efficiency of the individual decision-making unit (DMU) or on the calculation of the weights of multiple inputs or outputs, but pay little attention to the team interest of all the DMUs. Motivated by the idea of team reasoning, in which the benefit of the team is of higher importance than that of each individual, this paper considers all the DMUs as a team and introduces the team indexes including the overall efficiencies, the variance, the boundaries of all the DMUs, and the relationships between DMUs. Several models are first developed to estimate values of the team indexes based on which decision makers can provide their preferences regarding them. Then, models are established to obtain the interval efficiencies of individual DMUs under the condition that the team indexes are satisfied. Several examples are given to illustrate the proposed approaches and verify their applicability.
\end{abstract}

Key words: Data envelopment analysis; team reasoning; overall efficiency; variance; boundary; relationship.

\section{Introduction}

Data envelopment analysis (DEA), proposed by Charnes et al. (1978), is a non-parametric method for measuring the efficiency of the decision-making units (DMUs) by a set of inputs and a set of outputs. DEA requires no assumption for the functional relationships between inputs and outputs and allows individual DMUs to evaluate their efficiencies by choosing the most favorable input and output weights for themselves. It has been applied in many areas, such as the resource reallocation (Yua and Hsiao, 2015), the hospital assessment (Ghiyasi, 2016), and the assessment of public finance (Morenoá and Lozano, 2016). 
However, such an individual evaluation causes more than one DMU to be efficient, leading to them being unable to be fully discriminated (Wang et al., 2011). In addition, the flexibility in weighting multiple inputs and outputs sometimes produces unrealistic weight schemes. To overcome these disadvantages, the cross-efficiency evaluation method has been developed to rank DMUs based on cross-efficiency scores, which are linked to all DMUs (Sexton et al., 1986). Unfortunately, the cross-efficiency evaluations obtained from the original DEA are generally not unique because the optimal solution to the DEA linear programs is not unique. For this reason, Sexton et al. (1986) and Doyle and Green (1994) proposed secondary goals (the aggressive and benevolent formulations) to address this issue. Liang et al. (2008a) extended the model of Doyle and Green by introducing a number of different secondary objective functions, which include minimizing the total deviation from the ideal point, minimizing the maximum efficiency score, and minimizing the mean absolute deviation. Wang and Chin (2008a) proposed a neutral DEA model for cross-efficiency evaluation, which determines one set of input and output weights for each DMU from its own point of view without being aggressive or benevolent toward the other DMUs. Liang et al. (2008b) generalized the original DEA cross-efficiency concept to game cross-efficiency, in which each DMU seeks to maximize its own efficiency under the condition that the cross-efficiency of the other DMU does not deteriorate. Song and Liu (2016) proposed a data DEA cross-efficiency aggregation method based on Shannon entropy.

As a large number of zero weights may still exist among inputs and outputs, Bal (2008) proposed a simultaneous input- and output-oriented weight-determination DEA model for the cross-efficiency evaluation to reduce the number of zero weights. Similar approaches can be found in Ruiz and Sirvent (2012). Simar and Wilson (2015) estimated efficiency confidence intervals by using the bootstrap or other sub-sampling techniques. The weights for inputs and outputs of DMUs are estimated from a random sample of input-output combinations, which are obtained from existing production units operating in the studied activity sector. Salo and Punkka (2011) developed the ratio-based efficiencies (ranking intervals, dominance relations, and efficiency bounds) to compare the relative efficiencies of DMUs for all feasible inputoutput weights. Yang et al. (2012) considered all possible weight sets in the weight space when computing the cross-efficiency, which produces an interval cross-efficiency for each DMU. Alcaraz et al. (2013) developed a procedure to carry out the cross-efficiency evaluation without the need to make any specific choice of DEA weights. The proposed procedure takes into consideration all the possible choices of weights that all the DMUs can make, and yields a range of the possible rankings for each unit instead of a single ranking. It is necessary to note that the interval efficiencies (Salo and Punkka, 2011) are different from the efficiency confidence intervals (Simar and Wilson, 2015). The interval efficiencies contain all the possible efficiency scores of DMUs, including the best and worst efficiency scores from all possible weights in the weight space. The efficiency confidence intervals are defined from a probability point of view, according to which of the most efficient DMUs lie within an interval with a certain confidence 
level.

Many classical decision analysis methods, including DEA, are based on assumptions of rationality and certainty. However, numerous studies (Kahneman and Tversky, 1979) have demonstrated that these classical methods cannot explain many phenomena (such as Allais's Paradox and Ellsberg's Paradox) in real applications. Therefore, researchers have explored decision-making theories based on behavior (Ramos et al., 2014), and many behavioral decision theories have been developed, such as prospect theory (Kahneman and Tversky, 1979), regret theory (Loomes and Sugden, 1982; Bell, 1982), and fairness theory (Rabin, 1993). Colman et al. (2008a) noted that traditional decision and game theories rest on a fundamental assumption that players seek to maximize their individual utilities, but in some interactive decisions, it is observed and seems intuitively reasonable to maximize the utility of the group of players as a whole. Such phenomenon or thinking can be called team reasoning (Colman et al., 2003). Colman et al. (2008a) reported experimental evidence that suggests that team reasoning predicts strategic choices more powerfully than orthodox game theory in some games. Many researchers (Sugden, 2008; Krueger, 2008) commented on such an approach with varying mixtures of agreement and disagreement. In replying to these commentaries, Colman et al. (2008b) emphasized that decision makers sometimes act to maximize the collective payoff for a group, which cannot be explained in terms of standard social value orientations. Therefore, team reasoning is a distinctive and important mode of reasoning, which should be acknowledged in cognitive psychology and be added to the set of social value orientations used in social psychology. Furthermore, based on the experiments on how players use focal points to select equilibria in one-shot coordination games, Bardsley et al. (2009) tested the two alternative explanations, namely, the cognitive hierarchy theory and team reasoning, and found strong support for team reasoning. In addition, Gong et al. (2015a, 2015b) considered all the individuals forming a team, and developed consensus models based on the minimum cost of the team.

From the above literature review, we find that all the existing DEA approaches focus on the individual interest but ignore the team interest. Motivated by the idea of team reasoning, this paper investigates DEA models that put the team interest ahead of the individual interest. In DEA, all the DMUs can be considered as a team, and the interest of the team can be reflected by the team's indexes, such as the overall efficiency of all the DMUs, the deviations of DMUs, the boundaries of DMUs, and the relationship between DMUs in the team. The first three can be considered the external performance indexes of the team and expressed by interval values, whereas the fourth can be considered the internal performance index of the team, in which the relationship between DMUs is expressed by the interval pairwise comparison matrix (Saaty and Vargas, 1987) $\tilde{R}=\left(\tilde{r}_{i j}\right)_{n \times n}=\left(\left[r_{i j}^{-}, r_{i j}^{+}\right]\right)_{n \times n}$, where $\tilde{r}_{i j}$ is the relative efficiency value between each pair of DMUs. Based on such an idea, the following approach is proposed: First, the models are developed to estimate the values of the team indexes. Based on the obtained indexes, the decision makers can express their preferences about the indexes. Then, 
the individual models are developed to estimate the interval efficiencies of individual DMUs under the condition that the team indexes of DMUs are satisfied.

Following the approach proposed above, the structure of the paper is as follows: Section 2 gives some preliminaries; Section 3 establishes the models based on the overall efficiency of all the DMUs; Section 4 develops the models based on the variance of all the DMUs; Section 5 focuses on the boundaries of all the DMUs; in Section 6, the models based on the relationship between DMUs are investigated; and Section 7 provides the conclusions.

\section{Preliminaries}

Consider $n$ DMUs that are to be evaluated in terms of $m$ inputs and $s$ outputs. Let $x_{l i}(l=$ $1,2, \cdots, m)$ and $y_{r i}(r=1,2, \cdots, s)$ be the inputs and outputs for DMU $i$. Then the efficiency of DMU $i$ can be defined by the following equations:

$$
E_{i}=\frac{\sum_{r=1}^{s} u_{r} y_{r i}}{\sum_{l=1}^{m} v_{l} x_{l i}}, i=1,2, \cdots, n,
$$

where $u_{r}$ and $v_{l}$ are variable output and input weights, respectively.

According to Charnes et al. (1978), the best relative efficiency $E_{d d}$ of DMU $d$ can be measured by the following CCR model:

$$
\begin{array}{ll}
\text { (MOD 1) } \max & E_{d d}=\sum_{r=1}^{s} u_{r d} y_{r d} \\
\text { s.t. } & \sum_{l=1}^{m} v_{l d} x_{l d}=1 \\
& \sum_{r=1}^{s} u_{r d} y_{r i}-\sum_{l=1}^{m} v_{l d} x_{l i} \leq 0, i=1,2, \ldots, n \\
& u_{r d} \geq 0, r=1,2, \ldots, s \\
& v_{l d} \geq 0, l=1,2, \ldots, m
\end{array}
$$

For DMU $d(d=1,2, \cdots, n)$, the group of optimal weights $u_{1 d}^{*}, u_{2 d}^{*}, \cdots, u_{s d}^{*}$ and $v_{1 d}^{*}, v_{2 d}^{*}, \cdots, v_{m d}^{*}$ can be obtained by solving (MOD 1), and its cross-efficiency toward DMU $i$, namely, $E_{d i}$, can be calculated as follows using the weights of DMU $d$ :

$$
E_{d i}=\frac{\sum_{r=1}^{s} u_{r d}^{*} y_{r i}}{\sum_{l=1}^{m} v_{l d}^{*} x_{l i}}, d, i=1,2, \cdots, n
$$


Then, the average of all $E_{d i}(d=1,2, \cdots, n)$, namely, $\bar{E}_{i}=\frac{1}{n} \sum_{d=1}^{n} E_{d i}(i=1,2, \cdots, n)$, can be used as a new efficiency measure, called the cross-efficiency score for DMU $i$.

(MOD 1) may have multiple optimal solutions, which will reduce the usefulness of crossefficiency evaluation. To resolve this drawback, Sexton et al. (1986) and Doyle and Green (1994) introduced several secondary goals. The most commonly used secondary goals are shown below:

$$
\begin{aligned}
& \text { (MOD 2) } \max [\min ] \sum_{r=1}^{s} u_{r d}\left(\sum_{i=1, i \neq d}^{n} y_{r i}\right) \\
& \text { s.t. } \sum_{l=1}^{m} v_{l d}\left(\sum_{i=1, i \neq d}^{n} x_{l i}\right)=1 \\
& \sum_{r=1}^{s} u_{r d} y_{r i}-\sum_{l=1}^{m} v_{l d} x_{l i} \leq 0, i=1,2, \ldots, n \\
& \sum_{r=1}^{s} u_{r d} y_{r d}-E_{d d} \sum_{l=1}^{m} v_{l d} x_{l d}=0 \\
& u_{r d} \geq 0, r=1,2, \ldots, s \\
& v_{l d} \geq 0, l=1,2, \ldots, m
\end{aligned}
$$

(MOD 2) includes two cases: maximization and minimization of the cross-efficiencies of other DMUs, which are called the benevolent strategy and aggressive strategy, respectively. When the weights are calculated using different strategies, different results may be obtained. Although the aggressive strategy for cross-efficiency evaluation is chosen and utilized in most applications, there is no theoretical evidence to support such a choice (Wang and Chin, 2010b).

Many methods have been developed to improve the above models. For example, Liang et al. (2008a) extended the model of Doyle and Green (1994) by introducing three different secondary goals, which are minimizing the total deviation from the ideal point, minimizing the maximum efficiency score, and minimizing the mean absolute deviation. Wang and Chin (2010a) proposed a neutral DEA model for cross-efficiency evaluation, which determines one set of input and output weights for each DMU from its own point of view without being aggressive or benevolent toward the other DMUs.

As stated in the introduction, although many methods have been developed to improve DEA models, all the methods focus on the efficiencies of individual DMUs rather than the overall efficiency of DMUs. However, quite often decision makers may not only attempt to maximize their individual expected utilities but also try to maximize the collective utility (Hurley, 2005). Decision making based on such collective preferences is called team reasoning (Colman et al., 2003), which is very different from individual utility maximization. Theories of team reasoning generally assume that decision makers are motivated to maximize either collective or individual utilities depending on the circumstances (Gold and Sugden, 2007; Gong, 2017). 
Motivated by team reasoning, we will develop team-reasoning-based DEA models in the following sections.

\section{DEA models based on overall efficiency of DMUs}

If we consider all the DMUs as a team, then the overall efficiency of the team can be represented as $E=\frac{\sum_{i=1}^{n} \sum_{r=1}^{s} u_{r} y_{r i}}{\sum_{i=1}^{n} \sum_{l=1}^{m} v_{l} x_{l i}}$. Therefore, the following model can be established to derive the interval of $E$ :

$$
\begin{aligned}
& \text { (MOD 3) } \max [\min ] \frac{\sum_{i=1}^{n} \sum_{r=1}^{s} u_{r} y_{r i}}{\sum_{i=1}^{n} \sum_{l=1}^{m} v_{l} x_{l i}} \\
& \text { s.t. } \quad \sum_{r=1}^{s} u_{r} y_{r j}-\sum_{l=1}^{m} v_{l} x_{l j} \leq 0, j=1,2, \cdots, n \\
& \sum_{i=1}^{n} \sum_{r=1}^{s} u_{r} y_{r i}+\sum_{i=1}^{n} \sum_{l=1}^{m} v_{l} x_{l i}=n \\
& u_{r} \geq \frac{1}{(m+s) \max _{j}\left\{y_{r j}\right\}}, r=1,2, \ldots, s \\
& v_{l} \geq \frac{1}{(m+s) \max _{i}\left\{x_{l i}\right\}}, l=1,2, \ldots, m
\end{aligned}
$$

In (MOD3), the overall efficiency of all the DMUs is minimized or maximized. The normalization constraint $\sum_{i=1}^{n} \sum_{r=1}^{s} u_{r} y_{r i}+\sum_{i=1}^{n} \sum_{l=1}^{m} v_{l} x_{l i}=n$ is introduced to avoid unbounded solutions for the weights (Wang et al., 2011), and the constraints $u_{r} \geq \frac{1}{(m+s) \max _{j}\left\{y_{r j}\right\}}$ and $v_{l} \geq \frac{1}{(m+s) \max _{i}\left\{x_{l i}\right\}}$ are included to make sure that $u_{r}$ and $v_{r}$ are always positive (Sueyoshi, 1999).

Since $\sum_{i=1}^{n} \sum_{r=1}^{s} u_{r} y_{r i}+\sum_{i=1}^{n} \sum_{l=1}^{m} v_{l} x_{l i}=n$, we have

$$
\frac{\sum_{i=1}^{n} \sum_{r=1}^{s} u_{r} y_{r i}}{\sum_{i=1}^{n} \sum_{l=1}^{m} v_{l} x_{l i}}=\frac{n-\sum_{i=1}^{n} \sum_{l=1}^{m} v_{l} x_{l i}}{\sum_{i=1}^{n} \sum_{l=1}^{m} v_{l} x_{l i}}=\frac{n}{\sum_{i=1}^{n} \sum_{l=1}^{m} v_{l} x_{l i}}-1 .
$$

This implies that the model given in (MOD 3) can be rewritten as the following equivalent model:

$$
\text { (MOD 4) } \max [\min ] \sum_{i=1}^{n} \sum_{l=1}^{m} v_{l} x_{l i}
$$

s.t. the constraints in (MOD 3) are satisfied.

The above models can be solved using the Linear Interactive and General Optimizer 14 
(LINGO 14). Suppose the obtained maximum and minimum values of the overall efficiency of DMUs are denoted by $E^{*}$ and $E_{*}$ respectively.

With the availability of the overall efficiency range $\left[E_{*}, E^{*}\right]$, a DEA model considering both the overall efficiency and individual efficiency of DMUs can be developed. The detailed approach is as follows: First, the decision makers can select an interval $\left[E^{-}, E^{+}\right] \subset\left[E_{*}, E^{*}\right]$ to express their preferences about the overall efficiency of DMUs. Then, the efficiency of each individual DMU can be evaluated under the condition that the overall efficiency is guaranteed to be within the preferred range $\left[E^{-}, E^{+}\right]$. Such an approach can be formulated by the following model:

(MOD 5) $\max [\min ] \frac{\sum_{r=1}^{s} u_{r} y_{r i}}{\sum_{l=1}^{m} v_{l} x_{l i}}$

s.t. the constraints in (MOD 3) are satisfied and

$$
E_{*} \leq E^{-} \leq \frac{\sum_{i=1}^{n} \sum_{r=1}^{s} u_{r} y_{r i}}{\sum_{i=1}^{n} \sum_{l=1}^{m} v_{l} x_{l i}} \leq E^{+} \leq E^{*}
$$

In (MOD 5), the interval efficiency of each individual DMU is obtained under the condition that the overall efficiency belongs to the interval $\left[E^{-}, E^{+}\right]$. In particular, if $\left[E^{-}, E^{+}\right]=\left[E_{*}, E^{*}\right]$, then there is no requirement on the overall efficiency; if $\left[E^{-}, E^{+}\right]=\left[E^{*}, E^{*}\right]$, then the overall efficiency of DMUs should attain its maximum value; if $\left[E^{-}, E^{+}\right]=\left[E^{*}, E^{*}\right]$, then the overall efficiency of DMUs should attain its minimum value. For convenience, let $E^{-}=E^{+}=$ $\alpha E_{*}+(1-\alpha) E^{*}$. Then $\alpha(0 \leq \alpha \leq 1)$ can be considered the preferred ratio to be assigned or chosen by decision makers.

To compare interval efficiencies of individual DMUs, we first introduce the following definition. Let $a=\left[a^{-}, a^{+}\right]$and $b=\left[b^{-}, b^{+}\right]$be any two interval values, where $0 \leq a^{-}<a^{+} \leq 1$ and $0 \leq b^{-}<b^{+} \leq 1$. Then the possibility degree (Facchinetti et al., 1998) that $a$ is superior to $b, p_{a \succ b}$, is defined as

$$
p_{a \succ b}=\frac{\max \left\{0, a^{+}-b^{-}\right\}-\max \left\{0, a^{-}-b^{+}\right\}}{a^{+}-a^{-}+b^{+}-b^{-}}
$$

which can be denoted by $a \stackrel{p_{a \succ b}}{\succ} b$ and should satisfy the following properties:

1) $0 \leq p_{a \succ b} \leq 1$; 2) $p_{a \succ b} \geq 0.5$ if and only if $\frac{a^{-}+a^{+}}{2} \geq \frac{b^{-}+b^{+}}{2}$, and $p_{a \succ b}=0.5$ if and only if $\frac{a^{-}+a^{+}}{2}=\frac{b^{-}+b^{+}}{2}$.

From the second property of the possibility degree formula, it is implied that the bigger the median value of an interval value is, the bigger the interval value is. Therefore, the median value of the interval value can be used to compare interval values for convenience. In the following, we consider the numerical example provided by Wong and Beasley (1990) to 
illustrate the proposed methods:

Example 1 (Wong and Beasley, 1990). Efficiency evaluation of seven departments in a university: Seven academic departments (DMUs) in a university are evaluated in terms of the three inputs and outputs given below, with their input and output data given in Table 1 together with the target efficiencies of the seven academic departments.

Input 1: Total number of academic staff.

Input 2: Academic staff salaries in thousands of pounds.

Input 3: Support staff salaries in thousands of pounds.

Output 1: Total number of undergraduate students.

Output 2: Total number of postgraduate students.

Output 3: Total number of research papers.

Table 1. Data for seven departments in a university

\begin{tabular}{ccccccc}
\hline DMUs & Input 1 & Input 2 & Input 3 & Output 1 & Output 2 & Output 3 \\
\hline 1 & 12 & 400 & 20 & 60 & 35 & 17 \\
2 & 19 & 750 & 70 & 139 & 41 & 40 \\
3 & 42 & 1500 & 70 & 225 & 68 & 75 \\
4 & 15 & 600 & 100 & 90 & 12 & 17 \\
5 & 45 & 2000 & 250 & 253 & 145 & 130 \\
6 & 19 & 730 & 50 & 132 & 45 & 45 \\
7 & 41 & 2350 & 600 & 305 & 159 & 97 \\
\hline \multicolumn{7}{r}{ Note. The data in Table 1 are taken from Wong and Beasley (1990). }
\end{tabular}

Note. The data in Table 1 are taken from Wong and Beasley (1990).

By solving (MOD 4), we obtain $E_{*}=0.3275$ and $E^{*}=0.9066$. If all the DMUs are considered as a team, then the minimum efficiency of the team is 2.2078 , which may be adopted by completely pessimistic decision makers, whereas the maximum efficiency of the team is 6.1845 , which may be selected by completely optimistic decision makers. Suppose that the decision makers require the overall efficiency of the team to be bigger than 0.9 , that is, $\left[E^{-}, E^{+}\right]=[0.9,0.9066]$. Solving (MOD 5) under such a condition, the interval efficiencies of individual DMUs and the rankings are given in Table 2.

Table 2. The interval efficiencies of individual DMUs obtained by (MOD 5) with $\left[E^{-}, E^{+}\right]=[0.9,0.9066]$

\begin{tabular}{cccccccc}
\hline DMUs & 1 & 2 & 4 & 5 & 6 & 7 \\
\hline Efficiencies & {$[0.8861,0.9499]$} & {$[0.9393,0.9593]$} & {$[0.7470,0.7623]$} & {$[0.5507,0.5892]$} & {$[0.9819,1.0000]$} & {$[0.9877,1.0000]$} & {$[0.9533,0.9851]$} \\
\hline Rankings & & $6{ }^{0.5954} 5{ }^{0.9359} 7^{0.8842}{ }^{0.87735}$ & ${ }^{1.0000}{ }_{3}^{1.0000}{ }_{4}$ & $\succ$ & \\
\hline
\end{tabular}

In (MOD 5), let $E^{-}=E^{+}=\alpha E_{*}+(1-\alpha) E^{*}, 0 \leq \alpha \leq 1$. When $\alpha$ is assigned different values, the interval efficiencies of individual DMUs can be derived by (MOD 5), which are listed in Table 3.

Table 3. The interval efficiencies of individual DMUs obtained by (MOD 5) 


\begin{tabular}{ccccccc}
\hline \multirow{2}{*}{ DMUs } & \multicolumn{7}{c}{$\alpha$} \\
\cline { 2 - 7 } & 0 & 0.2 & 0.3 & 0.5 & 0.8 & 1 \\
\hline 1 & 0.9153 & {$[0.6691,1.0000]$} & {$[0.6219,1.0000]$} & {$[0.5285,1.0000]$} & {$[0.3908,0.8796]$} & 0.4389 \\
2 & 0.9543 & {$[0.7662,0.9578]$} & {$[0.7123,0.9285]$} & {$[0.6050,0.8600]$} & {$[0.4453,0.6433]$} & 0.3983 \\
3 & 0.7584 & {$[0.6125,0.8177]$} & {$[0.5689,0.8386]$} & {$[0.4825,0.8981]$} & {$[0.3549,0.7568]$} & 0.3816 \\
4 & 0.5715 & {$[0.3755,0.6393]$} & {$[0.3503,0.5866]$} & {$[0.3012,0.4810]$} & {$[0.2327,0.3218]$} & 0.2041 \\
5 & 1.0000 & {$[0.8033,0.9769]$} & {$[0.7483,0.9099]$} & {$[0.6384,0.7722]$} & {$[0.4740,0.5466]$} & 0.3755 \\
6 & 1.0000 & {$[0.8305,1.0000]$} & {$[0.7705,1.0000]$} & {$[0.6515,1.0000]$} & {$[0.4749,0.7992]$} & 0.4542 \\
7 & 0.9851 & {$[0.6443,0.9081]$} & {$[0.5418,0.8420]$} & {$[0.3863,0.7081]$} & {$[0.2610,0.5021]$} & 0.2460 \\
\hline
\end{tabular}

Now the possibility degree formula (Facchinetti et al., 1998) is used to compare the interval efficiencies of individual DMUs and the median values of interval efficiencies, and the resulting rankings of DMUs are listed in Table 4.

Table 4. The median values of the interval efficiencies of DMUs in Table 3

\begin{tabular}{|c|c|c|c|c|c|c|c|c|}
\hline \multirow{2}{*}{$\alpha$} & \multicolumn{7}{|c|}{ DMUs } & \multirow{2}{*}{ Rankings } \\
\hline & 1 & 2 & 3 & 4 & 5 & 6 & 7 & \\
\hline 0 & 0.9153 & 0.9543 & 0.7584 & 0.5715 & 1.000 & 1.000 & 0.9851 & 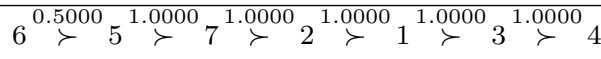 \\
\hline 0.2 & 0.8346 & 0.8621 & 0.7152 & 0.5075 & 0.8902 & 0.9153 & 0.7762 & $6 \stackrel{0.5733}{\succ} 5 \stackrel{0.5769}{\succ} 2 \stackrel{0.5525}{\succ} 1{ }^{0.5981} 7{ }^{0.6303} 3^{0.9429}{ }^{0.9}$ \\
\hline 0.3 & 0.8110 & 0.8204 & 0.7038 & 0.4685 & 0.8291 & 0.8853 & 0.6919 & 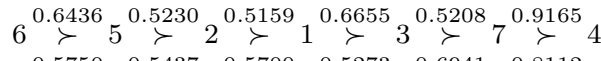 \\
\hline 0.5 & 0.7643 & 0.7325 & 0.6903 & 0.3911 & 0.7053 & 0.8258 & 0.5472 & $6 \stackrel{0.5750}{\succ} 1 \stackrel{0.5437}{\succ} 2 \stackrel{0.5700}{\succ} 5 \stackrel{0.5273}{\succ} 3 \stackrel{0.6941}{\succ} 7 \stackrel{0.8112}{\succ} 4$ \\
\hline 0.8 & 0.6352 & 0.5443 & 0.5559 & 0.2773 & 0.5103 & 0.6371 & 0.3816 & $6 \stackrel{0.5023}{\succ} 1 \stackrel{0.5891}{\succ} 3 \stackrel{0.5193}{\succ} 2 \stackrel{0.6256}{\succ} 5 \underbrace{0.9104} 7 \stackrel{0.8159}{\succ} 4$ \\
\hline 1.0 & 0.4389 & 0.3983 & 0.3816 & 0.2041 & 0.3755 & 0.4542 & 0.2460 & $6 \stackrel{1.0000}{\succ} 1{ }^{1.0000}{ }^{1.0000}{ }^{1.00} 3^{1.0000} 5^{1.0000} 7^{1.0000} \succ_{4}$ \\
\hline
\end{tabular}

From Table 4, it is noted that, as the value of the parameter $\alpha$ changes, the ranking of DMUs also changes, which reflects the impact of the different preferences of the decision makers. Most of the median values of the interval efficiencies decrease as the value of $\alpha$ increases.

Let $\left[E^{-}, E^{+}\right]=\left[E_{*}, E^{*}\right]$ and $\left[E^{-}, E^{+}\right]=\left[E^{*}, E^{*}\right]$ in (MOD 5), respectively. Then the maximum efficiency of each DMU can be obtained as listed in Table 5. The corresponding overall efficiency of all the DMUs can also be calculated.

Table 5. The maximum efficiencies of individual DMUs obtained by (MOD 5)

\begin{tabular}{cccccccc}
\hline \multirow{2}{*}[E^{-},E^{+}]{} & \multicolumn{7}{c}{ DMUs } \\
\cline { 2 - 7 } & 1 & 2 & 3 & 4 & 5 & 6 & 7 \\
\hline$\left[E_{*}, E^{*}\right]$ & $1(0.8769)$ & $0.9853(0.8609)$ & $0.9402(0.7303)$ & $0.6799(0.8609)$ & $1(0.8835)$ & $1(0.8835)$ & $0.9851(0.8835)$ \\
\hline$E^{*}$ & $0.9153(0.9066)$ & $0.9543(0.9066)$ & $0.7584(0.9066)$ & $0.5715(0.9066)$ & $1.0000(0.9066)$ & $1.0000(0.9066)$ & $0.9851(0.9066)$ \\
\hline Note: The values in parentheses indicate the corresponding overall efficiency of all the DMUs. & &
\end{tabular}

In Table 5, we find that if $\left[E^{-}, E^{+}\right]=\left[E_{*}, E^{*}\right]$, then DMUs $1,2,3$, and 4 can attain their best performances, but the overall efficiency of all the DMUs cannot. If $\left[E^{-}, E^{+}\right]=\left[E^{*}, E^{*}\right]$, DMUs 1, 2, 3, and 4 cannot reach their best performances, but the overall efficiency of all the DMUs can. Therefore, this example illustrates the need for and usefulness of (MOD 5) to balance the overall and individual efficiencies. 


\section{DEA models based on the variance of DMUs}

The models developed in Section 3 are based on the overall efficiency of all the DMUs, which can also be interpreted as the average efficiency of the team. In contrast, this section will develop another essential measure: the variance of DMUs. In other words, models based on the variance of the team will be established.

Let $\lambda_{i}=\sum_{l=1}^{m} v_{l} x_{l i}-\sum_{r=1}^{s} u_{r} y_{r i}$. Then $\left|\lambda_{i}-\lambda_{j}\right|$ measures the variance between DMU $i$ and $\operatorname{DMU} j$, and $\sum_{j=1}^{n} \sum_{i=1}^{n}\left|\lambda_{i}-\lambda_{j}\right|$ measures the variance of all the DMUs. Then, the following models are given to estimate the interval value of the variance of all the DMUs (i.e., the variance of the team):

$$
\begin{aligned}
& \text { (MOD 6) } \max [\min ] \sum_{j=1}^{n} \sum_{i=1}^{n}\left|\lambda_{i}-\lambda_{j}\right| \\
& \text { s.t. } \quad \text { the constraints in (MOD 3) are satisfied and } \\
& \sum_{l=1}^{m} v_{l} x_{l i}-\sum_{r=1}^{s} u_{r} y_{r i}=\lambda_{i}
\end{aligned}
$$

Let $\varphi_{i j}=\frac{1}{2}\left(\left|\lambda_{i}-\lambda_{j}\right|+\lambda_{i}-\lambda_{j}\right)$ and $\phi_{i j}=\frac{1}{2}\left(\left|\lambda_{i}-\lambda_{j}\right|-\left(\lambda_{i}-\lambda_{j}\right)\right)$. Then $\varphi_{i j}+\phi_{i j} \leq$ $\lambda_{i}+\lambda_{j}, \varphi_{i j}+\phi_{i j} \leq \max \left\{\lambda_{i}, \lambda_{j}\right\}$, and $\varphi_{i j}-\phi_{i j}=\lambda_{i}-\lambda_{j}$. The following model can be given: .

$$
\begin{aligned}
& \left(\text { MOD 7) } \min \sum_{j=1}^{n} \sum_{i=1}^{n}\left(\varphi_{i j}+\phi_{i j}\right)\right. \\
& \text { s.t. the constraints in (MOD 3) are satisfied and } \\
& \sum_{l=1}^{m} v_{l} x_{l i}-\sum_{r=1}^{s} u_{r} y_{r i}=\lambda_{i} \\
& \varphi_{i j}-\phi_{i j}=\lambda_{i}-\lambda_{j} \\
& \varphi_{i j} \geq 0, \phi_{i j} \geq 0, \lambda_{i} \geq 0, \lambda_{j} \geq 0
\end{aligned}
$$

By solving (MOD 6) and (MOD 7), we obtain the minimum and maximum variances among all the DMUs (i.e., the team), denoted as $\delta_{*}$ and $\delta^{*}$, respectively. The decision makers can select any subinterval of $\left[\delta_{*}, \delta^{*}\right]$ to express their preference or constraint on the overall variance among all the DMUs. Certainly, the variance among all the DMUs should be bigger than $\delta^{-}$and smaller than $\delta^{+}$, where $\delta_{*} \leq \delta^{-} \leq \delta^{+} \leq \delta^{*}$. Once the preferred interval of the overall variance is chosen, the model that can derive the interval efficiencies of individual DMUs under the constrained overall variance can be formulated as follows: 


$$
\begin{aligned}
& \text { (MOD 8) } \max [\min ] \quad \frac{\sum_{r=1}^{s} u_{r} y_{r i}}{\sum_{l=1}^{m} v_{l} x_{l i}} \\
& \text { s.t. } \quad \text { the constraints in }(\text { MOD 3) are satisfied and } \\
& \sum_{l=1}^{m} v_{l} x_{l i}-\sum_{r=1}^{s} u_{r} y_{r i}=\lambda_{i} \\
& \varphi_{i j}-\phi_{i j}=\lambda_{i}-\lambda_{j} \\
& \varphi_{i j} \geq 0, \phi_{i j} \geq 0, \lambda_{i} \geq 0, \lambda_{j} \geq 0 \\
& \delta^{-} \leq \sum_{j=1}^{n} \sum_{i=1}^{n}\left(\varphi_{i j}+\phi_{i j}\right) \leq \delta^{+}
\end{aligned}
$$

. In (MOD 8), the interval efficiencies of individual DMUs are derived under the condition or constraint that the overall variance of the team should lie in the interval $\left[\delta^{-}, \delta^{+}\right]$. In particular, if $\left[\delta^{-}, \delta^{+}\right]=\left[\delta_{*}, \delta^{*}\right]$, then there is no constraint on the variance of the team; if $\left[\delta^{-}, \delta^{+}\right]=\left[\delta_{*}, \delta_{*}\right]$, then the variance of the team is restricted to its minimum value; and if $\left[\delta^{-}, \delta^{+}\right]=\left[\delta^{*}, \delta^{*}\right]$, then the variance of the team is allowed to attain its maximum value. For convenience, let $\delta^{-}=\delta^{+}=\beta \delta_{*}+(1-\beta) \delta^{*}, 0 \leq \beta \leq 1$. Then the decision makers' preference about the variation can be reflected by $\beta$.

Now the model proposed above is applied to Example 1 given in Section 3. Suppose that the decision makers focus on the variance of the team. Then, by solving (MOD 7), the minimum and maximum variances of the team can be obtained as $\delta_{*}=2.9114$ and $\delta^{*}=27.3703$, respectively. If decision makers do not mind the big variance, then $\delta^{*}=27.3703$ can be chosen. In contrast, if the smaller variance is regarded as better, then $\delta_{*}=2.9114$ can be

\begin{tabular}{|c|c|c|c|c|c|c|c|}
\hline DMUs & 1 & 2 & 3 & 4 & 5 & 6 & 7 \\
\hline Efficiencies & {$[0.7820,0.9212]$} & {$[0.9448,0.9853]$} & {$[0.7501,0.7786]$} & {$[0.5740,0.6799]$} & {$[0.8853,0.9908]$} & {$[0.9840,1.000]$} & {$[0.8845,0.9775]$} \\
\hline Rankings & & & $6 \stackrel{0.9770}{\succ} 2 \stackrel{0.684}{\succ}$ & $\stackrel{0.5355}{\succ} 7 \stackrel{0.8419}{\succ} 1$ & $\succ^{0000} 3 \stackrel{1.0000}{\succ} 4$ & & \\
\hline
\end{tabular}
chosen. Suppose the decision makers require that the variance of the team be smaller than 3 , that is, $\left[\delta^{-}, \delta^{+}\right]=[2.9114,3]$. Then the interval efficiencies of individual DMUs under the chosen constraint on the variance can be calculated by (MOD 8), and the results are listed in Table 6 .

Table 6. The interval efficiencies of individual DMUs obtained by (MOD 8) with $\left[\delta^{-}, \delta^{+}\right]=[2.9114,3]$

To make the decision more flexible, a parameter $\beta$ is defined to trade off between these two extreme situations, that is, $\delta^{-}=\delta^{+}=\beta \delta_{*}+(1-\beta) \delta^{*}$. The decision makers can interact with the decision process by assigning different values to $\beta$. Once the value of $\beta$ is given, the interval efficiencies of individual DMUs can be calculated by (MOD 8), which are shown in Table 7. The median values and the rankings of DMUs are listed in Table 8.

Table 7. The interval efficiencies of individual DMUs obtained by (MOD 8) 


\begin{tabular}{ccccccc}
\hline \multirow{2}{*}{ DMUs } & \multicolumn{7}{c}{$\beta$} \\
\cline { 2 - 7 } & 0 & 0.1 & 0.4 & 0.7 & 0.9 & 1 \\
\hline 1 & 0.6321 & {$[0.5437,0.7503]$} & {$[0.3683,1.0000]$} & {$[0.3719,1.0000]$} & {$[0.5621,1.0000]$} & 0.8070 \\
2 & 0.4650 & {$[0.4402,0.5594]$} & {$[0.3717,0.8382]$} & {$[0.4424,0.9162]$} & {$[0.6476,0.9668]$} & 0.9835 \\
3 & 0.5652 & {$[0.4866,0.6676]$} & {$[0.3284,0.9210]$} & {$[0.3367,0.8481]$} & {$[0.5168,0.8117]$} & 0.7763 \\
4 & 0.1905 & {$[0.1924,0.2409]$} & {$[0.1994,0.4081]$} & {$[0.2395,0.5402]$} & {$[0.4000,0.6555]$} & 0.6733 \\
5 & 0.3918 & {$[0.3862,0.4689]$} & {$[0.3678,0.7282]$} & {$[0.4636,0.8761]$} & {$[0.7096,1.0000]$} & 0.8959 \\
6 & 0.5944 & {$[0.5386,0.7032]$} & {$[0.4063,1.0000]$} & {$[0.4496,1.0000]$} & {$[0.6988,1.0000]$} & 1.0000 \\
7 & 0.1951 & {$[0.2093,0.2336]$} & {$[0.2783,0.3662]$} & {$[0.4489,0.5370]$} & {$[0.6681,0.7619]$} & 0.8895 \\
\hline
\end{tabular}

Table 8. The median values of the interval efficiencies of individual DMUs in Table 7

\begin{tabular}{|c|c|c|c|c|c|c|c|c|}
\hline \multirow{2}{*}{$\beta$} & \multicolumn{7}{|c|}{ DMUs } & \multirow{2}{*}{ Rankings } \\
\hline & 1 & 2 & 3 & 4 & 5 & 6 & 7 & \\
\hline 0.0 & 0.6321 & 0.4650 & 0.5652 & 0.1905 & 0.3918 & 0.5944 & 0.1951 & $1 \stackrel{1.0000}{\succ} 6 \stackrel{1.0000}{\succ} 3 \stackrel{1.0000}{\succ} 2 \stackrel{1.0000}{\succ} 5 \stackrel{1.0000}{\succ} 7 \stackrel{1.0000}{\succ} 4$ \\
\hline 0.1 & 0.6470 & 0.4998 & 0.5771 & 0.2167 & 0.4276 & 0.6209 & 0.2215 & $1 \succ^{0.5703} 6 \underbrace{0.6267}_{\succ} 3 \succ^{0.7575} 2 \underbrace{0.8579} 5 \underbrace{1.0000}_{\succ} 7 \underbrace{0.5659} 4$ \\
\hline 0.4 & 0.6842 & 0.6050 & 0.6247 & 0.3038 & 0.5480 & 0.7032 & 0.3223 & $6 \underbrace{0.5155}_{\succ} 1 \stackrel{0.5486}{\succ}^{0.5186} \stackrel{\succ}{\succ}^{0.5689} 5^{1.0000} 7^{0.5624} 4$ \\
\hline 0.7 & 0.6860 & 0.6793 & 0.5924 & 0.3899 & 0.6699 & 0.7248 & 0.4930 & $6 \succ_{\succ}^{0.5330} 1 \succ_{\succ}^{0.5060} 2 \underbrace{0.5107}_{\succ} 5 \underbrace{0.5838} 3 \underbrace{0.6659} 7{ }_{\succ}^{0.7652} 4$ \\
\hline 0.9 & 0.7811 & 0.8072 & 0.6643 & 0.5278 & 0.8548 & 0.8494 & 0.7150 & $5 \stackrel{0.5091}{\succ} 6 \stackrel{0.5680}{\succ} 2 \stackrel{0.5345}{\succ} 1 \stackrel{0.6242}{\succ} 7 \stackrel{0.6306}{\succ} 3 \stackrel{0.7480}{\succ} 4$ \\
\hline 1.0 & 0.8070 & 0.9835 & 0.7763 & 0.6733 & 0.8959 & 1.0000 & 0.8895 & 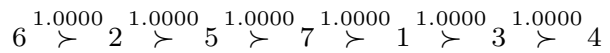 \\
\hline
\end{tabular}

From Table 8, it is found that most of the median values of the interval efficiencies increase as the value of $\beta$ increases.

Consider the cases $\left[\delta^{-}, \delta^{+}\right]=\left[\delta_{*}, \delta^{*}\right]$ and $\left[\delta^{-}, \delta^{+}\right]=\left[\delta_{*}, \delta_{*}\right]$ in (MOD 8). Then, the maximum efficiency of each DMU can be obtained, and the corresponding variance of DMUs can also be calculated. The results are listed in Table 9.

Table 9. The maximum efficiencies of individual DMUs obtained by (MOD 8)

\begin{tabular}{cccccccc}
\hline \multirow{2}{*}[\delta^{-},\delta^{+}]{} & \multicolumn{7}{c}{$D M U s$} \\
\cline { 2 - 7 } & 1 & 2 & 3 & 4 & 5 & 6 & 7 \\
\hline$\left[\delta_{*}, \delta^{*}\right]$ & $1(14.6013)$ & $0.9853(2.9541)$ & $0.9402(19.1327)$ & $0.6799(2.9541)$ & $1(4.1100)$ & $1(14.6013)$ & $0.9851(3.0816)$ \\
\hline$\left[\delta_{*}, \delta_{*}\right]$ & $0.3007(2.9114)$ & $0.3398(2.9114)$ & $0.2712(2.9114)$ & $0.2045(2.9114)$ & $0.3719(2.9114)$ & $0.3585(2.9114)$ & $0.3613(2.9114)$ \\
\hline
\end{tabular}

From Table 9 , it is found that if $\left[\delta^{-}, \delta^{+}\right]=\left[\delta_{*}, \delta^{*}\right]$, then all DMUs attain their best performances, but the minimum variances of DMUs are very large; if $\left[\delta^{-}, \delta^{+}\right]=\left[\delta_{*}, \delta_{*}\right]$, DMUs cannot reach their best performances, but the variance of all the DMUs is restricted to its minimum value.

\section{DEA models based on the boundaries of the team}

In addition to the mean discussed in Section 3 and variance in Section 4, another useful team index is the boundaries of DMUs. For example, decision makers may require that the efficiency of each individual DMU not be smaller (or bigger) than some value. The following model is proposed to derive the maximum lower boundary of DMUs. 
(MOD 9) $\max \lambda$

s.t. the constraints in (MOD 3) are satisfied and

$$
\frac{\sum_{r=1}^{s} u_{r} y_{r i}}{\sum_{l=1}^{m} v_{l} x_{l i}} \geq \lambda
$$

To solve (MOD 9) is to maximize the minimum efficiency across all individual DMUs (i.e., the lower efficiency bound of the team), which is very similar to the payoff matrix in game theory; that is, the bigger the efficiency of each individual DMU, the better. Suppose that the optimal value of (MOD 9) is $\lambda_{*}$. Then decision makers can choose a value not bigger than $\lambda_{*}$ as the minimum efficiency bound that all individual DMUs need to meet or surpass, i.e., $\dot{\lambda}\left(0 \leqslant \dot{\lambda} \leqslant \lambda_{*}\right)$. Under such a condition or restriction on the minimum efficiency for the team, the following model can be constructed to derive the interval efficiencies of individual DMUs:

$$
\begin{aligned}
& \text { (MOD 10) } \max [\min ] \frac{\sum_{r=1}^{s} u_{r} y_{r i}}{\sum_{l=1}^{m} v_{l} x_{l i}} \\
& \text { s.t. } \quad \text { the constraints in (MOD 3) are satisfied and } \\
& \quad \sum_{r=1}^{s} u_{r} y_{r i} \geqslant \dot{\lambda} \sum_{l=1}^{m} v_{l} x_{l i}
\end{aligned}
$$

In other words, the above model can be used to derive the interval efficiency of each DMU under the constraint that all DMUs meet the required minimal level of efficiency.

Contrary to (MOD 9), if decision makers consider DMUs from a loss performance point of view, then their aim could be to minimize the maximum value of the efficiency of individual DMUs, that is, the smaller the efficiency of an individual DMU, the better. To address such a situation from the team's point of view, the following model can be constructed:

$$
\begin{array}{ll}
\text { (MOD 11) } \min & \lambda \\
\text { s.t. } & \text { the constraints in (MOD 3) are satisfied and } \\
& \frac{\sum_{r=1}^{s} u_{r} y_{r i}}{\sum_{l=1}^{m} v_{l} x_{l i}} \leqslant \lambda
\end{array}
$$

By solving (MOD 11), the minimum upper boundary across all DMUs can be obtained. Suppose that the optimal value of (MOD 11) is $\lambda^{*}$. Then decision makers can provide a value not smaller than $\lambda^{*}$ as the maximum efficiency bound that no DMU should surpass, i.e., $\ddot{\lambda}\left(\lambda^{*} \leqslant \ddot{\lambda} \leqslant 1\right)$. Under such a condition or restriction on the maximum efficiency for the team, the following model can be constructed to derive the interval efficiencies of DMUs: 
(MOD 12) $\max [\min ] \frac{\sum_{r=1}^{s} u_{r} y_{r i}}{\sum_{l=1}^{m} v_{l} x_{l i}}$

s.t. the constraints in (MOD 3) are satisfied and

$$
\sum_{r=1}^{s} u_{r} y_{r i} \leqslant \ddot{\lambda} \sum_{l=1}^{m} v_{l} x_{l i}
$$

If decision makers have some requirements across all DMUs in the team, for example, the minimum (or maximum) efficiency of each DMU should be at a certain value, then (MOD 9) or (MOD 11) can be used to obtain such boundaries for the team of DMUs. (MOD 9) can be used to maximize the minimum efficiency value across all DMUs, from which the biggest value of the lower boundary for all the DMUs, denoted by $\lambda_{*}$, can be obtained; (MOD 11) can be used to minimize the maximum efficiency value across all DMUs, from which the smallest value of the upper boundary for all DMUs, denoted by $\lambda^{*}$, can be obtained.

Now, the models proposed above are applied to further analyze the case given in Example 1. First, it is obtained that $\lambda_{*}=0.6799$ and $\lambda^{*}=0.3691$ by (MOD 9) and (MOD 11). Suppose that the decision makers provide the value $\alpha \lambda_{*}$, where $0 \leqslant \alpha \leqslant 1, \lambda^{*}(1+\beta)$, and $0 \leqslant \beta \leqslant \frac{1}{\lambda^{*}}-1$, to describe their preferences about the boundaries of DMUs. Then the interval efficiencies of individual DMUs can be calculated by (MOD 10) and (MOD 12). The results are listed in Tables 10 and 11, and the median values and rankings of DMUs are listed in Tables 12 and 13 .

Table 10. The interval efficiencies of individual DMUs obtained by (MOD 10)

\begin{tabular}{ccccccc}
\hline \multirow{2}{*}{ DMUs } & \multicolumn{7}{c}{$\alpha$} \\
\cline { 2 - 7 } & 1 & 0.95 & 0.9 & 0.85 & 0.8 & 0.75 \\
\hline 1 & 0.8001 & {$[0.7633,0.8865]$} & {$[0.7267,0.9263]$} & {$[0.6903,0.9662]$} & {$[0.6540,1.0000]$} & {$[0.6179,1.0000]$} \\
2 & 0.9853 & {$[0.9385,0.9853]$} & {$[0.8919,0.9853]$} & {$[0.8454,0.9853]$} & {$[0.7989,0.9853]$} & {$[0.7525,0.9853]$} \\
3 & 0.7774 & {$[0.7403,0.8142]$} & {$[0.7033,0.8236]$} & {$[0.6664,0.8343]$} & {$[0.6297,0.8450]$} & {$[0.5931,0.8544]$} \\
4 & 0.6799 & {$[0.6459,0.6799]$} & {$[0.6119,0.6799]$} & {$[0.5779,0.6799]$} & {$[0.5439,0.6799]$} & {$[0.5099,0.6799]$} \\
5 & 0.8892 & {$[0.8101,0.9252]$} & {$[0.7746,0.9612]$} & {$[0.7391,0.9972]$} & {$[0.7037,1.0000]$} & {$[0.6684,1.0000]$} \\
6 & 1.0000 & {$[0.9533,1.0000]$} & {$[0.9067,1.0000]$} & {$[0.8602,1.0000]$} & {$[0.8139,1.0000]$} & {$[0.7677,1.0000]$} \\
7 & 0.8940 & {$[0.7056,0.9226]$} & {$[0.6451,0.9512]$} & {$[0.5892,0.9797]$} & {$[0.5439,0.9851]$} & {$[0.5099,0.9851]$} \\
\hline
\end{tabular}

Table 11. The median values of the interval efficiencies of individual DMUs in Table 10 


\begin{tabular}{|c|c|c|c|c|c|c|c|c|}
\hline \multirow{2}{*}{$\alpha$} & \multicolumn{7}{|c|}{ DMUs } & \multirow{2}{*}{ Rankings } \\
\hline & 1 & 2 & 3 & 4 & 5 & 6 & 7 & \\
\hline 1 & 0.8002 & 0.9852 & 0.7774 & 0.6798 & 0.8892 & 1.0000 & 0.8940 & $6 \stackrel{1.0000}{\succ} 2 \stackrel{1.0000}{\succ} 7{ }^{1.0000} 5{ }^{1.0000} \succ{ }^{1.0000} \succ{ }^{1.0000} 4$ \\
\hline 0.95 & 0.8249 & 0.9619 & 0.7773 & 0.6629 & 0.8677 & 0.9767 & 0.8141 & $6 \stackrel{0.6578}{\succ} 2 \stackrel{1}{\succ}^{1.0000} 5 \stackrel{0.6794}{\succ}^{0.5317} 7^{0.6267} \stackrel{\succ}{\succ}^{1.0000} 4$ \\
\hline 0.90 & 0.8265 & 0.9386 & 0.7634 & 0.6459 & 0.8679 & 0.9533 & 0.7982 & $6 \stackrel{0.5790}{\succ} 2 \stackrel{0.7525}{\succ}^{0.6072} \stackrel{\succ}{\succ}^{0.5561} 7^{0.5814}{ }^{0.0000} 4$ \\
\hline 0.85 & 0.8282 & 0.9154 & 0.7504 & 0.6289 & 0.8681 & 0.9301 & 0.7844 & $\left.6 \stackrel{0.5527}{\succ}^{0.0 .6186} 5^{0.5747} \stackrel{\succ}{\succ}^{0.5657} 7^{0.5611}\right)^{0.9500} 4$ \\
\hline 0.80 & 0.8270 & 0.8921 & 0.7373 & 0.6119 & 0.8519 & 0.9069 & 0.7645 & $6 \stackrel{0.5399}{\succ} 2 \stackrel{0.5834}{\succ} 5 \stackrel{0.5387}{\succ} 1 \stackrel{0.5794}{\succ} 7 \stackrel{0.5414}{\succ} 3 \stackrel{0.8571}{\succ} 4$ \\
\hline 0.75 & 0.8090 & 0.8689 & 0.7238 & 0.5949 & 0.8342 & 0.8839 & 0.7475 & 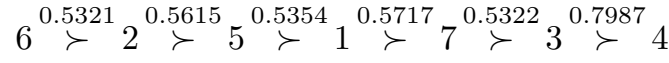 \\
\hline
\end{tabular}

Table 12. The interval efficiencies of individual DMUs obtained by (MOD 12)

\begin{tabular}{ccccccc}
\hline \multirow{2}{*}{ DMUs } & \multicolumn{7}{c}{$\beta$} \\
\cline { 2 - 7 } & 0 & 0.05 & 0.1 & 0.15 & 0.2 & 0.25 \\
\hline 1 & 0.3204 & {$[0.3007,0.3580]$} & {$[0.3007,0.3822]$} & {$[0.3007,0.4056]$} & {$[0.3007,0.4289]$} & {$[0.3007,0.4522]$} \\
2 & 0.3475 & {$[0.3398,0.3671]$} & {$[0.3398,0.3866]$} & {$[0.3398,0.4062]$} & {$[0.3398,0.4253]$} & {$[0.3398,0.4439]$} \\
3 & 0.2844 & {$[0.2712,0.3083]$} & {$[0.2712,0.3281]$} & {$[0.2712,0.3481]$} & {$[0.2712,0.3688]$} & {$[0.2712,0.3901]$} \\
4 & 0.2083 & {$[0.1905,0.2235]$} & {$[0.2011,0.2387]$} & {$[0.1988,0.2537]$} & {$[0.1975,0.3682]$} & {$[0.1964,0.2821]$} \\
5 & 0.3691 & {$[0.3646,0.3876]$} & {$[0.3646,0.4061]$} & {$[0.3646,0.4245]$} & {$[0.3646,0.4430]$} & {$[0.3646,0.4614]$} \\
6 & 0.3691 & {$[0.3585,0.3876]$} & {$[0.3585,0.4061]$} & {$[0.3583,0.4245]$} & {$[0.3583,0.4430]$} & {$[0.3583,0.4614]$} \\
7 & 0.3368 & {$[0.3039,0.3782]$} & {$[0.2831,0.3980]$} & {$[0.2666,0.4178]$} & {$[0.2530,0.4371]$} & {$[0.2418,0.4561]$} \\
\hline
\end{tabular}

Table 13. The median values of the interval efficiencies of individual DMUs in Table 12

\begin{tabular}{|c|c|c|c|c|c|c|c|c|}
\hline \multirow{2}{*}{$\beta$} & \multicolumn{7}{|c|}{ DMUs } & \multirow{2}{*}{ Rankings } \\
\hline & 1 & 2 & 3 & 4 & 5 & 6 & 7 & \\
\hline 0 & 0.3204 & 0.3474 & 0.2844 & 0.2084 & 0.3690 & 0.3690 & 0.3368 & $6 \stackrel{1.0000}{\succ} 5 \stackrel{1.0000}{\succ} 2 \stackrel{1.0000}{\succ} 7 \stackrel{1.0000}{\succ} 1 \stackrel{1.0000}{\succ} 3 \stackrel{1.0000}{\succ} 4$ \\
\hline 0.05 & 0.3294 & 0.3534 & 0.2898 & 0.2070 & 0.3761 & 0.3730 & 0.3410 & $5 \stackrel{0.5585}{\succ} 6 \stackrel{0.8475}{\succ} 2 \stackrel{0.6220}{\succ} 7 \stackrel{0.5889}{\succ} 1 \stackrel{0.9195}{\succ}^{1.00000} 4$ \\
\hline 0.10 & 0.3415 & 0.3632 & 0.2996 & 0.2199 & 0.3853 & 0.3823 & 0.3406 & $5 \stackrel{0.5342}{\succ}^{0.0 .7023} 2^{0.6401} 7^{0.4954} \stackrel{0}{\succ}^{0.8020} 3 \stackrel{1}{\succ}^{1.0000} 4$ \\
\hline 0.15 & 0.3532 & 0.3730 & 0.3096 & 0.2263 & 0.3945 & 0.3914 & 0.3422 & $5 \stackrel{0.5250}{\succ} 6 \stackrel{0.6388}{\succ} 2 \stackrel{0}{\succ}^{0.6415} 7^{0.4572}{ }^{0.7393}{ }^{1.0000} 4$ \\
\hline 0.20 & 0.3648 & 0.3826 & 0.3200 & 0.2829 & 0.4038 & 0.4007 & 0.3450 & $5 \stackrel{0.5193}{\succ} 6 \stackrel{0.6063}{\succ} 2 \stackrel{0.6391}{\succ}^{0.0 .4368} \stackrel{0}{\succ}^{0.6984} 3 \stackrel{0.6385}{\succ} 4$ \\
\hline 0.25 & 0.3765 & 0.3919 & 0.3307 & 0.2393 & 0.4130 & 0.4098 & 0.3489 & $5 \stackrel{0.5158}{\succ} 6 \stackrel{0.5869}{\succ} 2 \stackrel{0}{\succ}^{0.6347} 7^{0.4248} 1 \stackrel{0.6694}{\succ}^{0.94467} 4$ \\
\hline
\end{tabular}

Based on Table 11, it is found that most of the median values of the interval efficiencies increase as the value of $\alpha$ increases. Based on Table 13, it is found that most of the median values of the interval efficiencies increase as the value of $\beta$ increases.

\section{DEA models based on the relationships between D- MUs in the team}

In Sections 3, 4 and 5, the overall efficiency, the variance and the boundaries of DMUs can be considered as the external performance indexes for DMUs in a team. On the other hand, the DMUs in a team have relationships between each other, and such relationships can be utilized to form an internal performance index for DMUs as a team. In this section, we employ the 
interval pairwise comparison matrix (Saaty and Vargas, 1987) to develop the relationship index between DMUs in a team.

Suppose that the efficiency of DMU $i$ is denoted by $E_{i}$. Then for each pair of DMUs $i$ and $j$, the relative efficiency value between them can be written as

$$
\frac{E_{i}}{E_{j}}=\frac{\sum_{r=1}^{s} u_{r} y_{r i}}{\sum_{l=1}^{m} v_{l} x_{l i} v_{l=1}^{m} v_{l j} u_{r} y_{r j}}
$$

As the values of $x_{l i}(l=1,2, \cdots, m)$ and $y_{r i}(r=1,2, \cdots, s)$ are given, the interval value of $\frac{E_{i}}{E_{j}}$ can be obtained as $r_{i j}=\left[r_{i j}^{-}, r_{i j}^{+}\right]$, in which $r_{i j}^{+}$and $r_{i j}^{-}$are calculated by the following models:

$$
\text { (MOD 13) } \max [\min ] \frac{E_{i}}{E_{j}}=\frac{\sum_{r=1}^{s} u_{r} y_{r i}}{\sum_{l=1}^{m} v_{l} x_{l i}} \times \frac{\sum_{l=1}^{m} v_{l} x_{l j}}{\sum_{r=1}^{s} u_{r} y_{r j}}
$$

s.t. the constraints in (MOD 3) are satisfied.

All $\tilde{r}_{i j}$ can construct a matrix $\tilde{R}=\left(\tilde{r}_{i j}\right)_{n \times n}=\left(\left[r_{i j}^{-}, r_{i j}^{+}\right]\right)_{n \times n}$. Then $\tilde{r}_{i j}$ can express the preference degree of DMU $i$ over DMU $j$. It is easy to find that $r_{i j}^{-} r_{j i}^{+}=1$ and $r_{i i}^{-}=r_{i i}^{+}=1$ for $i, j=1,2, \ldots, n$. Therefore, $\tilde{R}$ is an interval comparison matrix (Saaty and Vargas, 1987) and can reflect the relationships between DMUs. For Example 1, given in Section $3, \tilde{R}$ can be calculated by (MOD 13) as follows:

$\tilde{R}=\left(\begin{array}{ccccccc}{[1,1]} & {[0.8120,1.4951]} & {[0.9677,1.4459]} & {[1.1769,3.9305]} & {[0.6919,1.6347]} & {[0.7432,1.1709]} & {[0.8285,3.2402]} \\ {[0.6689,1.2315]} & {[1,1]} & {[0.8223,1.2687]} & {[1.4493,2.6289]} & {[0.8187,1.3128]} & {[0.7768,0.9853]} & {[0.8426,2.4249]} \\ {[0.6916,1.0334]} & {[0.7882,1.2161]} & {[1,1]} & {[1.1435,3.0759]} & {[0.6552,1.5025]} & {[0.7370,0.9509]} & {[0.6743,2.8981]} \\ {[0.2544,0.8497]} & {[0.3803,0.6900]} & {[0.3251,0.8745]} & {[1,1]} & {[0.3972,0.7999]} & {[0.2979,0.6799]} & {[0.4168,1.1337]} \\ {[0.6117,1.4453]} & {[0.7618,1.2214]} & {[0.6656,1.5262]} & {[1.2501,2.5175]} & {[1,1]} & {[0.6257,1.1249]} & {[0.9928,2.1327]} \\ {[0.8540,1.3456]} & {[1.0149,1.2874]} & {[1.0516,1.3568]} & {[1.4709,3.3567]} & {[0.8890,1.5981]} & {[1,1]} & {[0.9146,3.0545]} \\ {[0.3086,1.2070]} & {[0.4124,1.1867]} & {[0.3450,1.4829]} & {[0.8821,2.3991]} & {[0.4689,1.0073]} & {[0.3274,1.0934]} & {[1,1]}\end{array}\right)$

Based on $\tilde{R}$, the decision makers can provide their preferences about the relationship between each pair of DMUs. Suppose that the decision makers provide their preferences about the relationship matrix between DMUs as $\tilde{A}=\left(\tilde{a}_{i j}\right)_{n \times n}=\left(\left[a_{i j}^{-}, a_{i j}^{+}\right]\right)_{n \times n}$, where $r_{i j}^{-} \leqslant a_{i j}^{-} \leqslant$ $a_{i j}^{+} \leqslant r_{i j}^{+}, a_{i j}^{-} a_{j i}^{+}=1$, and $a_{i i}^{-}=a_{i i}^{+}=1$ for $i, j=1,2, \ldots, n$. If there exists a vector $w=$ $\left(w_{1}, w_{2}, \cdots, w_{n}\right)^{\mathrm{T}}$ such that

$$
a_{i j}^{-} \leqslant \frac{w_{i}}{w_{j}} \leqslant a_{i j}^{+}, i, j=1,2, \ldots, n
$$

and $\sum_{i=1}^{n} w_{i}=1$, then $\tilde{A}$ is called a consistent interval pairwise comparison matrix (Arbel and Vargas, 1993). However, the elements of interval comparison matrix are given by the 
decision makers based on their experiences and expertise, and may be inconsistent due to the limitations of experiences and expertise as well as the complicated nature of decision problems (Ergu et al., 2011).

Suppose that the efficiency of DMU $i$ is denoted by $E_{i}$. If the interval pairwise comparison value between DMU $i$ and DMU $j$ is given as $a_{i j}=\left[\begin{array}{ll}a_{i j}^{-} & a_{i j}^{+}\end{array}\right]$, then it is desired that the following equation hold:

$$
a_{i j}^{-} \leqslant \frac{E_{i}}{E_{j}} \leqslant a_{i j}^{+}
$$

That is,

$$
a_{i j}^{-} \leqslant \frac{\sum_{r=1}^{s} u_{r} y_{r i} \sum_{l=1}^{m} v_{l} x_{l j}}{\sum_{r=1}^{s} u_{r} y_{r j} \sum_{l=1}^{m} v_{l} x_{l i}} \leqslant a_{i j}^{+}
$$

which can be rewritten as

$$
a_{i j}^{-} \sum_{r=1}^{s} u_{r} y_{r j} \sum_{l=1}^{m} v_{l} x_{l i} \leqslant \sum_{r=1}^{s} u_{r} y_{r i} \sum_{l=1}^{m} v_{l} x_{l j} \leqslant a_{i j}^{+} \sum_{r=1}^{s} u_{r} y_{r j} \sum_{l=1}^{m} v_{l} x_{l i}
$$

If it does not hold, then we should provide the deviation variances $d_{i j}^{-}$and $d_{i j}^{+}$, which satisfy

$$
a_{i j}^{-} \sum_{r=1}^{s} u_{r} y_{r j} \sum_{l=1}^{m} v_{l} x_{l i}-d_{i j}^{-} \leqslant \sum_{r=1}^{s} u_{r} y_{r i} \sum_{l=1}^{m} v_{l} x_{l j} \leqslant a_{i j}^{+} \sum_{r=1}^{s} u_{r} y_{r j} \sum_{l=1}^{m} v_{l} x_{l i}+d_{i j}^{+}
$$

where $d_{i j}^{-} \geqslant 0$ and $d_{i j}^{+} \geqslant 0$.

To minimize the overall deviation variables, the following model is constructed:

$$
\begin{array}{ll}
\text { (MOD 14) } \min & \sum_{i=1}^{n} \sum_{j=1}^{n}\left(d_{i j}^{-}+d_{i j}^{+}\right) \\
\text {s.t. } & a_{i j}^{-} \sum_{r=1}^{s} u_{r} y_{r j} \sum_{l=1}^{m} v_{l} x_{l i}-d_{i j}^{-} \leqslant \sum_{r=1}^{s} u_{r} y_{r i} \sum_{l=1}^{m} v_{l} x_{l j} \leqslant a_{i j}^{+} \sum_{r=1}^{s} u_{r} y_{r j} \sum_{l=1}^{m} v_{l} x_{l i}+d_{i j}^{+} \\
& d_{i j}^{-} \geqslant 0, d_{i j}^{+} \geqslant 0, i, j=1,2, \cdots, n
\end{array}
$$

(MOD 14) provides the decision makers the minimum value of the deviation variables, denoted by $d^{*}$, which can be used by the decision makers to choose an acceptable deviation level $d\left(d \leqslant d^{*}\right)$ for the team of DMUs. Then, the interval efficiencies of individual DMUs under the acceptable deviation level within the team can be calculated by the model below: 
(MOD 15) $\max [\min ] \frac{\sum_{r=1}^{s} u_{r} y_{r i}}{\sum_{l=1}^{m} v_{l} x_{l i}}$

s.t. $\sum_{i=1}^{n} \sum_{j=1}^{n}\left(d_{i j}^{-}+d_{i j}^{+}\right)=d$ and the constraints in (MOD 14) are satisfied.

Now the above models are applied to Example 1. Suppose that the decision makers provide the following matrix as their preferences about the relationships between DMUs according to $\tilde{R}$ :

$$
A=\left(\begin{array}{ccccccc}
{[1,1]} & {[5 / 6,4 / 3]} & {[1,4 / 3]} & {[2,3]} & {[3 / 4,3 / 2]} & {[3 / 4,1]} & {[1,3]} \\
{[3 / 4,6 / 5]} & {[1,1]} & {[1,5 / 4]} & {[3 / 2,2]} & {[1,5 / 4]} & {[4 / 5,5 / 6]} & {[1,2]} \\
{[3 / 4,1]} & {[4 / 5,1]} & {[1,1]} & {[2,3]} & {[1,3 / 2]} & {[4 / 5,5 / 6]} & {[3 / 4,2]} \\
{[1 / 3,1 / 2]} & {[1 / 2,2 / 3]} & {[1 / 3,1 / 2]} & {[1,1]} & {[2 / 5,3 / 5]} & {[2 / 5,3 / 5]} & {[1 / 2,1]} \\
{[2 / 3,3 / 4]} & {[4 / 5,1]} & {[2 / 3,1]} & {[5 / 3,5 / 2]} & {[1,1]} & {[4 / 5,1]} & {[1,2]} \\
{[1,4 / 3]} & {[6 / 5,5 / 4]} & {[6 / 5,5 / 4]} & {[5 / 3,5 / 2]} & {[1,5 / 4]} & {[1,1]} & {[2,3]} \\
{[1 / 3,1]} & {[1 / 2,1]} & {[1 / 2,4 / 3]} & {[1,2]} & {[1 / 2,1]} & {[1 / 3,1 / 2]} & {[1,1]}
\end{array}\right)
$$

By solving (MOD 14), we obtain the minimum deviation $J^{*}=1.9915$, which the decision makers can use to provide a feasible and acceptable deviation level $J\left(J \geqslant J^{*}\right)$, and then continue to calculate the interval efficiencies of individual DMUs under such a deviation constraint. By (MOD 15), the interval efficiencies of individual DMUs can be found in Table 14, and their median values and rankings are listed in Table 15. Based on Table 15, it is found that most of the median values of the interval efficiencies increase as the value of $J$ increases. That is, if we relax the deviation constraint (i.e., allow more diversity) within the team, the efficiency for each individual DMU can be improved.

Table 14. The interval efficiencies of individual DMUs obtained by (MOD 15)

\begin{tabular}{cccccc}
\hline \multirow{2}{*}{ DMUs } & \multicolumn{5}{c}{$J$} \\
\cline { 2 - 6 } & 1.9915 & 2.1 & 2.2 & 2.3 & 2.4 \\
\hline 1 & 0.4258 & {$[0.3563,0.5129]$} & {$[0.3211,0.5862]$} & {$[0.3060,0.6679]$} & {$[0.3007,0.7672]$} \\
2 & 0.4002 & {$[0.3677,0.4522]$} & {$[0.3499,0.5057]$} & {$[0.3425,0.5690]$} & {$[0.3398,0.6479]$} \\
3 & 0.3828 & {$[0.3206,0.4420]$} & {$[0.2886,0.4966]$} & {$[0.2758,0.5604]$} & {$[0.2712,0.6395]$} \\
4 & 0.1964 & {$[0.1944,0.2284]$} & {$[0.1935,0.2561]$} & {$[0.1930,0.2859]$} & {$[0.1926,0.3217]$} \\
5 & 0.3828 & {$[0.3667,0.4385]$} & {$[0.3646,0.4959]$} & {$[0.3646,0.5634]$} & {$[0.3646,0.6433]$} \\
6 & 0.4610 & {$[0.3999,0.5265]$} & {$[0.3725,0.5942]$} & {$[0.3623,0.6669]$} & {$[0.3585,0.7577]$} \\
7 & 0.2445 & {$[0.2255,0.2899]$} & {$[0.2183,0.3304]$} & {$[0.2140,0.3641]$} & {$[0.2103,0.3933]$} \\
\hline
\end{tabular}

Table 15. The median values of the interval efficiencies of DMUs in Table 14 


\begin{tabular}{|c|c|c|c|c|c|c|c|c|}
\hline \multirow{2}{*}{$J$} & \multicolumn{7}{|c|}{ DMUs } & \multirow{2}{*}{ Rankings } \\
\hline & 1 & 2 & 3 & 4 & 5 & 6 & 7 & \\
\hline 1.9915 & 0.4258 & 0.4002 & 0.3828 & 0.1964 & 0.3828 & 0.4610 & 0.2445 & $6 \stackrel{1.0000}{\succ} 1 \stackrel{1.0000}{\succ} 2 \stackrel{1.0000}{\succ} 5 \stackrel{1.0000}{\succ} 3 \stackrel{1.0000}{\succ} 7 \stackrel{1.0000}{\succ} 4$ \\
\hline 2.1 & 0.4346 & 0.4100 & 0.3813 & 0.2114 & 0.4026 & 0.4632 & 0.2577 & $6 \stackrel{0.6010}{\succ} 1 \stackrel{0.6022}{\succ} 2 \stackrel{0.5470}{\succ} 5 \stackrel{0.6102}{\succ} 3 \stackrel{1.0000}{\succ} 7 \stackrel{0.9705}{\succ} 4$ \\
\hline 2.2 & 0.4537 & 0.4278 & 0.3926 & 0.2248 & 0.4303 & 0.4834 & 0.2744 & $6 \stackrel{0.5610}{\succ} 1 \stackrel{0.5614}{\succ} 5 \stackrel{0.4915}{\succ} 2 \stackrel{0.6110}{\succ} 3 \stackrel{0.8694}{\succ} 7 \stackrel{0.7836}{\succ} 4$ \\
\hline 2.3 & 0.4870 & 0.4558 & 0.4181 & 0.2395 & 0.4640 & 0.5146 & 0.2891 & $6 \stackrel{0.5415}{\succ} 1 \stackrel{0.5409}{\succ} 5 \stackrel{0.5194}{\succ} 2 \stackrel{0.5737}{\succ}^{0.7969} 7^{0.7041} 4$ \\
\hline 2.4 & 0.5340 & 0.4939 & 0.4554 & 0.2572 & 0.5040 & 0.5581 & 0.3018 & $6 \stackrel{0.5279}{\succ} 1 \stackrel{0.5403}{\succ} 5 \stackrel{0.5172}{\succ} 2 \stackrel{0.5569}{\succ} 3 \stackrel{0.7785}{\succ} 7 \stackrel{0.6431}{\succ} 4$ \\
\hline
\end{tabular}

\section{Conclusions}

In this paper, the DEA methodology based on team reasoning has been investigated. All the DMUs have been considered as a team, and the indexes to measure the team, such as the overall efficiencies of DMUs, the variance of DMUs, the boundaries of DMUs, and the relationships between DMUs, have been defined. The models have been given to calculate the interval values of the team indexes, which can be used by the decision makers to provide their feasible preferences about the team's performance indexes. Furthermore, the models have been established to derive the interval efficiencies of individual DMUs under the condition that the constraints on the team indexes are satisfied. In the proposed models, the individual DMUs may not attain their maximum efficiencies, but they can make the team indexes attain their maximum values. In addition, the adjustable parameters, which can be used to trade off between the performances of the team and the individual DMUs, are given. A summary of the proposed models can be found in Table 16 .

By comparing the proposed methods with existing methods in the literature, we can draw the following conclusions:

The proposed DEA models pay more attention to the team than to the individual, while for the existing ones the opposite is true. In the proposed methods, the constraints on the team indexes, such as the overall efficiency, variance, and boundary among DMUs and the relationships between DMUs, should be satisfied before the interval efficiencies of individual DMUs are derived. This is distinctively different from the existing methods, in which the individual efficiencies are first derived and then the efficiencies of other DMUs are considered to avoid multiple solutions in the first stage.

The proposed DEA models can obtain the interval efficiencies of individual DMUs, taking into consideration all the risk preferences, whereas most of the existing DEA models focus only on the maximum efficiencies or the weights of inputs and outputs (Bal et al. 2008). In the proposed DEA models, decision makers can participate in the decision making by providing their requirements on the overall efficiency, the variance, the boundaries of DMUs and the relationships between DMUs, and can adjust the values of the parameters according to their preferences, which is not possible in the existing DEA models (Wang et al., 2011).

The proposed models do not have to calculate the weight vectors of DMUs, which reduces 
the amount of calculation, whereas in some existing models (Yang et al., 2012), the weight vector should be calculated to obtain the weight matrix and to then calculate the crossefficiencies of DMUs.

Table 16. Summary of the proposed models

\begin{tabular}{|c|c|c|c|c|}
\hline \multicolumn{4}{|c|}{ Models } & aims \\
\hline \multirow{11}{*}{$\begin{array}{l}\text { Team } \\
\text { reasoning }\end{array}$} & \multirow{8}{*}{$\begin{array}{l}\text { External } \\
\text { performance } \\
\text { indexes of } \\
\text { the team }\end{array}$} & \multirow{2}{*}{$\begin{array}{l}\text { Overall efficiencies } \\
\text { of the DMUs }\end{array}$} & $\begin{array}{l}\text { MOD } 3 \\
\text { MOD } 4\end{array}$ & $\begin{array}{l}\text { Maximize or minimize the overall } \\
\text { efficiencies of DMUs as a team }\end{array}$ \\
\hline & & & MOD 5 & $\begin{array}{l}\text { Maximize or minimize the } \\
\text { efficiencies of individual DMUs } \\
\text { under the constraints on the } \\
\text { overall efficiencies of DMUs }\end{array}$ \\
\hline & & \multirow{2}{*}{$\begin{array}{l}\text { Variance of } \\
\text { the DMUs }\end{array}$} & $\begin{array}{l}\text { MOD } 6 \\
\text { MOD } 7\end{array}$ & $\begin{array}{l}\text { Maximize or minimize the } \\
\text { variance of DMUs as a team }\end{array}$ \\
\hline & & & MOD 8 & $\begin{array}{l}\text { Maximize or minimize the efficiencies } \\
\text { of individual DMUs under the constraints } \\
\text { on the variance of DMUs }\end{array}$ \\
\hline & & \multirow{4}{*}{$\begin{array}{l}\text { Boundaries } \\
\text { of the DMUs }\end{array}$} & MOD 9 & $\begin{array}{l}\text { Maximize the minimum efficiency } \\
\text { across all individual DMUs } \\
\text { (i.e., maximize the lower efficiency } \\
\text { boundary of DMUs as a team) }\end{array}$ \\
\hline & & & MOD 10 & $\begin{array}{l}\text { Maximize or minimize the individual } \\
\text { efficiencies of DMUs under the constraints } \\
\text { on lower boundaries of DMUs }\end{array}$ \\
\hline & & & MOD 11 & $\begin{array}{l}\text { Minimize the maximum efficiency } \\
\text { across all individual DMUs (i.e., } \\
\text { minimize the upper efficiency boundary } \\
\text { of DMUs as a team) }\end{array}$ \\
\hline & & & MOD 12 & $\begin{array}{l}\text { Maximize or minimize the individual } \\
\text { efficiencies of DMUs under the constraints } \\
\text { on upper boundaries of DMUs }\end{array}$ \\
\hline & \multirow{3}{*}{$\begin{array}{l}\text { Internal } \\
\text { performance } \\
\text { indexes of } \\
\text { the team }\end{array}$} & \multirow{3}{*}{$\begin{array}{l}\text { Relationships } \\
\text { between DMUs }\end{array}$} & MOD 13 & $\begin{array}{l}\text { Maximize or minimize the relative efficiency } \\
\text { values between each pair of DMUs }\end{array}$ \\
\hline & & & MOD 14 & $\begin{array}{l}\text { Minimize the inconsistency or deviation of } \\
\text { the relationships between DMUs as a team }\end{array}$ \\
\hline & & & MOD 15 & $\begin{array}{l}\text { Maximize or minimize the efficiencies } \\
\text { of individual DMUs under the } \\
\text { constraints on the deviation of } \\
\text { relationships between DMUs }\end{array}$ \\
\hline
\end{tabular}




\section{Acknowledgments}

The authors would like to express their sincere thanks to the Editors and the anonymous reviewers for the excellent comments and valuable suggestions that helped us improve this paper. Meimei Xia was supported by the National Natural Science Foundation of China (Nos. 71501010, 71661167009), the Fundamental Funds for Humanities and Social Sciences of Beijing Jiaotong University (No. 2016JBZD01), and the China Scholarship Council. Jian Chen was supported by the National Natural Science Foundation of China (No. 71232007).

\section{References}

[1] J. Alcaraz, N. Ramn, J. L. Ruiz, I. Sirvent. Ranking ranges in cross-efficiency evaluations. European Journal of Operational Research 226 (2013) 516-521.

[2] H. Bal, H.H. Orkcu, S. Celebioglu. A new method based on the dispersion of weights in data envelopment analysis. Computers \& Industrial Engineering 54 (2008) 502-512.

[3] N. Bardsley, J. Mehta, R. Sugden. Explaining focal points: Cognitive hierarchy theory versus team reasoning. The Economic Journal 120 (2009) 40-79.

[4] D.E. Bell. Regret in decision making under uncertainty. Operations Research 30 (1982) 961-981.

[5] A. Charnes, W.W. Cooper, E. Rhodes. Measuring the efficiency of decision making units. European Journal of Operational Research 2 (1978) 429-444.

[6] A.M. Colman. Cooperation, psychological gametheory, and limitations of rationality in social interaction. Behavioral and Brain Sciences 26 (2003) 139-198.

[7] A.M. Colman, B.D. Pulford, J. Rose. Collective rationality in interactive decisions: Evidence for team reasoning. Acta Psychologica 128 (2008a) 387-397.

[8] A.M. Colman, B.D. Pulford, J. Rose. Team reasoning and collective rationality: Piercing the veil of obviousness. Acta Psychologica 128 (2008b) 409-412.

[9] J. Doyle, R. Green. Efficiency and cross-efficiency in DEA: Derivations, meanings and uses. Journal of the Operations Research Society 45 (1994) 567-578.

[10] D. Ergu, G. Kou, Y. Peng, Y. Shi. A simple method to improve the consistency ratio of the pair-wise comparison matrix in ANP. European Journal of Operational Research 213 (2011) 246-259.

[11] G. Facchinetti, R.G. Ricci, S Muzzioli. Note on ranking fuzzy triangular numbers. International Journal of Intelligent Systems 13 (1998) 613-622. 
[12] M. Ghiyasi. A DEA production technology and its usage for incorporation of collaboration in efficiency analysis: an axiomatic approach, International Transactions in Operational Research 00 (2016) 1-17, DOI: 10.1111/itor.12325.

[13] Z.W. Gong, X.X. Xu, H.H. Zhang, U. Aytun Ozturk, E. Herrera-Viedma, C. Xu. The consensus models with interval preference opinions and their economic interpretation. Omega 55 (2015a) 81-90.

[14] Z.W. Gong, H.H. Zhang a, J. Forrest, L.S. Li, X.X. Xu. Two consensus models based on the minimum cost and maximum return regarding either all individuals or one individual. European Journal of Operational Research 240 (2015b) 183-192.

[15] Z.W. Gong, C. Xu, F. Chiclana, X.X. Xu. Consensus measure with multi-stage fluctuation utility based on China's urban demolition negotiation. Group Decision and Negotiation 26 (2017) 379-407.

[16] N. Gold, R. Sugden. Collective intentions and team agency. Journal of Philosophy 104 (2007) 109-137.

[17] S. Hurley. Social heuristics that make us smarter. Philosophical Psychology 18 (2005) 585-611.

[18] D. Kahneman, A. Tversky. Prospect theory: an analysis of decision under risk. Econometrica 47 (1979) 263-291.

[19] J.I. Krueger. Methodological individualism in experimental games: Not so easily dismissed. Acta Psychologica 128 (2008) 398-401.

[20] L. Liang, J. Wu, W.D. Cook, J. Zhu. Alternative secondary goals in DEA cross efficiency evaluation. International Journal of Production Economics 113 (2008a) 1025-1030.

[21] L. Liang, J. Wu, W.D. Cook, J. Zhu. The DEA game cross-efficiency model and its Nash equilibrium. Operational Research 56 (2008b) 1278-1288.

[22] G. Loomes, R. Sugden, Regret theory: An alternative theory of rational choice under uncertainty, The Economic Journal 92 (1982) 805-824.

[23] P. Moreno and S. Lozano. Super SBI Dynamic Network DEA approach to measuring efficiency in the provision of public services. International Transactions in Operational Research 0 (2016) 1-21, DOI: 10.1111/itor.12257.

[24] M. Rabin. Incorporating fairness into game theory and economics. American Economic Review 83 (1993) 1281-1302. 
[25] G.M. Ramos, W. Daamen, S. Hoogendoorn. A state-of-the-art review: developments in utility theory, prospect theory and regret theory to investigate travellers' behaviour in situations involving travel time uncertainty, Transport Reviews 34 (2014) 46-67.

[26] J.L. Ruiz, I. Sirvent. On the DEA total weight flexibility and the aggregation in crossefficiency evaluations. European Journal of Operational Research 223 (2012) 732-738.

[27] T.L. Saaty, L.G. Vargas. Uncertainty and rank order in the analytic hierarchy process. European Journal of Operational Research 32 (1987) 107-117.

[28] A. Salo, A. Punkka. Ranking intervals and dominance relations for ratio-based efficiency analysis. Management Science 57 (2011) 200-214.

[29] L. Simar, P.W. Wilson. Statistical approaches for non-parametric frontier models: A guided tour, International Statistical Review 83 (2015) 77-110.

[30] L.L. Song, F, Liu. An improvement in DEA cross-efficiency aggregation based on the Shannon entropy. International Transactions in Operational Research 00 (2016) 1-10, DOI: $10.1111 /$ itor. 12361 .

[31] R. Sugden. Nash equilibrium, team reasoning and cognitive hierarchy theory. Acta Psychologica 128 (2008) 402-404.

[32] T.R. Sexton, R.H. Silkman, A.J. Hogan. Data envelopment analysis: Critique and extensions. In R. H. Silkman (Ed.), Measuring efficiency: An assessment of data envelopment analysis. San Francisco, CA: Jossey-Bass, 1986.

[33] T. Sueyoshi. DEA non-parametric ranking test and index measurement: Slack-adjusted DEA and an application to Japanese agriculture cooperatives. Omega 27(1999) 315-326

[34] Y.M. Wang, K.S. Chin. A neutral DEA model for cross-efficiency evaluation and its extension. Expert Systems with Applications 37 (2010a) 3666-3675.

[35] Y.M. Wang, K.S. Chin. Some alternative models for DEA cross-efficiency evaluation. International Journal of Production Economics 128 (2010b) 332-338.

[36] Y.M. Wang, Y Luo. Y.X Lan. Common weights for fully ranking decision making units by regression analysis. Expert Systems with Applications 38 (2011) 9122-9128.

[37] Y.H.B. Wong, J.E. Beasley. Restricting weight flexibility in data envelopment analysis. Journal of the Operational Research Society 41(1990) 829-835.

[38] F. Yang, S. Ang, Q. Xia, C. Yang. Ranking DMUs by using interval DEA cross efficiency matrix with acceptability analysis. European Journal of Operational Research 223 (2012) 483-488. 
[39] M.M. Yua, B. Hsiao. Single-phase slack-based centralized DEA for resource reallocation. International Transactions in Operational Research (2015) 1-15, DOI: 10.1111/itor.12210. 